\title{
Accumulation of 2-hydroxyglutarate in gliomas correlates with survival: a study by 3.0-tesla magnetic resonance spectroscopy
}

Manabu Natsumeda ${ }^{1}$, Hironaka Igarashi ${ }^{2 *}$, Toshiharu Nomura ${ }^{1}$, Ryosuke Ogura', Yoshihiro Tsukamoto ${ }^{1}$, Tsutomu Kobayashi ${ }^{1}$, Hiroshi Aoki ${ }^{1}$, Kouichirou Okamoto ${ }^{1}$, Akiyoshi Kakita ${ }^{3}$, Hitoshi Takahashi ${ }^{3}$, Tsutomu Nakada ${ }^{2}$ and Yukihiko Fujii

\begin{abstract}
Introduction: Previous magnetic resonance spectroscopy (MRS) and mass spectroscopy studies have shown accumulation of 2-hydroxyglutarate $(2 \mathrm{HG})$ in mutant isocitrate dehydrogenase (IDH) gliomas. IDH mutation is known to be a powerful positive prognostic marker in malignant gliomas. Hence, $2 \mathrm{HG}$ accumulation in gliomas was assumed to be a positive prognostic factor in gliomas, but this has not yet been proven. Here, we analyzed 52 patients harboring World Health Organization (WHO) grade II and III gliomas utilizing 3.0-tesla MRS.

Results: Mutant IDH gliomas showed significantly higher accumulation of $2 \mathrm{HG}$ (median 5.077 vs. 0.000, $p=0.0002$, Mann-Whitney test). $2 \mathrm{HG}$ was detectable in all mutant IDH gliomas, whereas in 10 out of 27 (37.0\%) wild-type IDH gliomas, $2 \mathrm{HG}$ was below the detectable range $(2 \mathrm{HG}=0)(p=0.0003$, chi-squared test). Screening for IDH mutation by $2 \mathrm{HG}$ analysis was highly sensitive (cutoff $2 \mathrm{HG}=1.489 \mathrm{mM}$, sensitivity $100.0 \%$, specificity $72.2 \%$ ). Gliomas with high $2 \mathrm{HG}$ accumulation had better overall survival than gliomas with low $2 \mathrm{HG}$ accumulation ( $p=0.0401$, Kaplan-Meier analysis).

Discussion: $2 \mathrm{HG}$ accumulation detected by 3.0-tesla MRS not only correlates well with IDH status, but also positively correlates with survival in WHO grade II and III gliomas.
\end{abstract}

Keywords: Glioma, MRS, 2-hydroxyglutarate, IDH mutation, Prognostic marker

\section{Introduction}

A comprehensive genomic analysis of glioblastomas has shown that mutations of isocitrate dehydrogenase $(I D H)$ are found in a subset of glioblastoma [1], and subsequent studies have found $I D H$ mutation to be a powerful prognostic factor in malignant gliomas [2], suggesting that $I D H$ mutations represent a clinically distinct subset of gliomas. The accumulation of 2-hydroxyglutarate (2HG) is noted in the cytoplasm of glioma cells with $I D H 1$ mutation and in the mitochondria of cells with $I D H 2$ mutation (Figure 1) [3]. Magnetic resonance spectroscopy (MRS) [4-10] as well as mass spectrometry [3,10-12] are known to effectively measure $2 \mathrm{HG}$ in glioma tissues with good correlations to $I D H$ mutation status. 2HG is an oncometabolite,

\footnotetext{
* Correspondence: higara@bri.niigata-u.ac.jp

${ }^{2}$ Center for Integrated Brain Sciences, Brain Research Institute, University of Niigata, Niigata, Japan

Full list of author information is available at the end of the article
}

which has been shown to cause tumorigenesis by inhibition of histone demethylation [13-15] and DNA demethylation [16,15]. 2HG accumulation in gliomas was assumed to positively correlate with patient survival because of the correlation of $I D H$ status to patient survival in malignant gliomas. However, to date, this has not been proven. In the present study, 2HG accumulation was shown to have a positive correlation with overall patient survival in WHO grade II and III gliomas for the first time.

\section{Materials and methods \\ Participants}

Seventy-one adult patients harboring World Health Organization (WHO) grade II or III gliomas, receiving magnetic resonance spectroscopy (MRS) evaluation at the Center for Integrated Brain Science, University of Niigata, before surgery and surgical treatment at the Department of Neurosurgery, University of Niigata, 


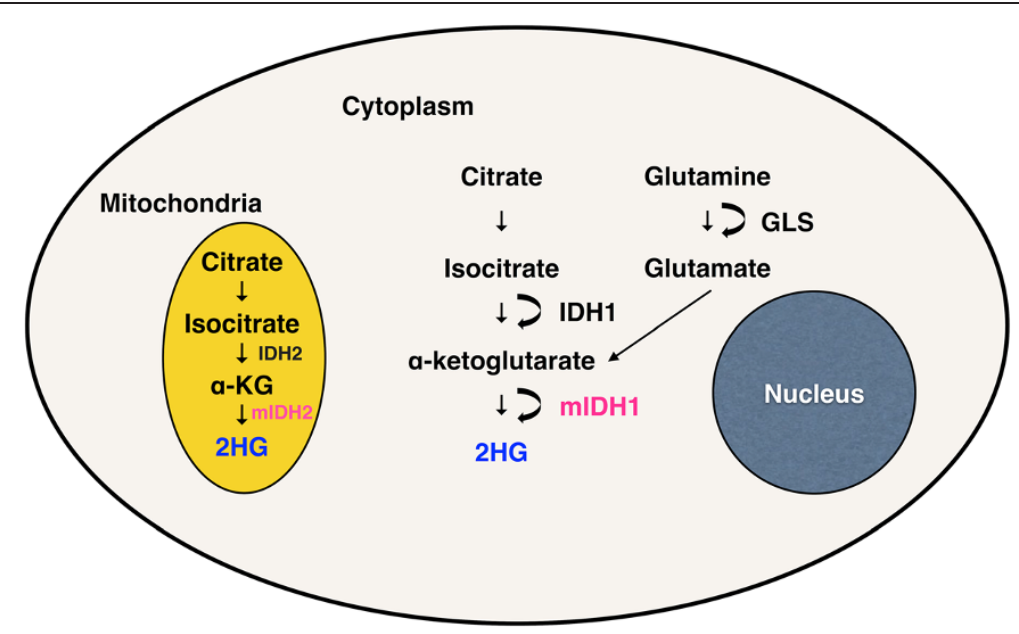

Figure 1 Schematic representation of $2 \mathrm{HG}$ production in $\mathrm{IDH}$ mutant gliomas. Accumulation of $2 \mathrm{HG}$ is seen in the cytoplasm of mutant IDH1 and mitochondria of mutant IDH2 gliomas. $2 \mathrm{HG}$ is also derived from glutamine in mutant IDH gliomas.

from December 2006 to March 2013 were included in the study. Patients with non-astrocytic, non-oligodendroglial, and non-oligoastrocytic tumors (e.g. ependymomas, $n=11$ ), patients whose MRS scans had low signal-to-noise ratios $(\mathrm{S} / \mathrm{N})$ of less than $4(\mathrm{n}=4)$, patients having a glioblastomalike single voxel MRS (SVMRS) spectra at relapse reflecting radiation necrosis or malignant transformation $(\mathrm{n}=2)$, a patient harboring a cystic lesion with insufficient volume of a solid component $(\mathrm{n}=1)$, and a patient lost to follow up $(n=1)$, were excluded from the analysis. Thus, a total of 52 patients were ultimately analyzed. Written informed consent was obtained from all of the participants in accordance with the human research guidelines of the Internal Review Board of University of Niigata.

\section{MRS analysis}

MRI $/{ }^{1} \mathrm{H}$-MRS was performed using a 3.0-tesla system (Signa LX, General Electric, Waukesha, WI) with an 8 channel phased array coil head. First, proton density images (Fast Spin Echo; TR/TE =5000/40; FOV: $20 \times$ $20 \mathrm{~mm}$; matrix: $256 \times 256$; slice thickness: $5 \mathrm{~mm}$; inter slice gap: $2.5 \mathrm{~mm}$ ) were taken. The slice with the largest depiction of tumor on proton density images was selected for SVMRS. A point-resolved spectroscopic sequence (PRESS), with chemical-shift-selective water suppression was used with the following parameters: (TR: $1.5 \mathrm{~s}$; TE: $30 \mathrm{~ms}$; data point 512 ; spectral width $1000 \mathrm{~Hz}$; number of acquisitions: 128-196; volume of interest (VOI): 12-20 × $12-20 \times 12-20 \mathrm{~mm})$.

Spectral analysis was performed using LCModel version 6.3 (Stephen Provencher, Oakville, Ontario, Canada) [17]. This software automatically adjusts the phase and chemical shift of the spectra, estimates the baseline, and performs eddy current corrections. Relative metabolite concentrations and their uncertainties were estimated by fitting the spectrum to a basis set of spectra acquired from individual metabolites in solution. The basis set was made with MR experiment simulation software (GAMMA, Radiology, Duke University Medical Center, Durham, NC) and provided by Dr.Steven Provencher [17] and was calibrated with MRS phantom solution (18-cm-diameter MRS HDsphere, model 2152220; General Electric, Milwaukee, WI) using our MR system. Nineteen metabolites were included in this LCModel basis set: alanine, aspartate, creatine $(\mathrm{Cr})$, phosphocreatine $(\mathrm{PCr}), \gamma$ - aminobutyric acid, glucose, glutamine (Gln), glutamate (Glu), glycerophosphocholine (GPC), phosphocholine (PC), gluthathione (GSH), 2-hydroxyglutarate (2HG), myo-inositol (Ins), lactate, NAA (N-acetylaspartate), N-acetylaspartylglutamate (NAAG), scyllo-inositol, taurine, and guanine. Total NAA (tNAA: the sum of NAA and NAAG), total choline (tCho: the sum of GPC and PC), total creatine (tCr: the sum of $\mathrm{Cr}$ and PCr), and sum of Glu and Gln (Glx) were noted. To calculate the absolute metabolite concentrations, an unsuppressed water signal was used as a reference.

Quantification estimates of metabolites were considered unreliable and excluded when Cramer-Rao lower bounds, returned as the percentage of standard deviation (\%SD) by LCModel, was greater than $35 \%$, as previously described [18]. Because low 2HG and GSH estimates yielded large $\% \mathrm{SDs}$ (i.e. when $2 \mathrm{HG}=0, \% \mathrm{SD}=\infty$ ), the above exclusion criteria was applied only when the estimated 2HG amount was greater than $1.0 \mathrm{mM}$ or GSH was greater than $0.5 \mathrm{mM}$. Glx and tNAA were excluded when \%SD was greater than 30\%; tCho and $\mathrm{tCr}$ were excluded when $\%$ SD was greater than $20 \%$.

\section{Pathological analysis and IDH analysis}

Surgical specimens were analyzed by two pathologists (H.T. and A.K.) and diagnosed according to the WHO 
classification [19]. IDH1 R132H immunohistochemical (IHC) analysis (H09 clone, Dianova, Hamburg, Germany; 1:100) was performed in formalin-fixed, paraffin imbedded section using the avidin-biotin-peroxide method (Vector, Burlingame, CA, USA) with diaminobenzidine as the chromogen and counterstained with hematoxylin.

For cases showing negative staining for IDH1 R132H, DNA sequencing for IDH1 and IDH2 was analyzed. Genomic DNA was extracted from paraffin-embedded sections, and as described previously [20,21], PCR amplification was performed by using primer sets (forward: 5'CGGTCTTCAGAGAAGCCATT-3', and reverse 5'-TT CATACCTTGCTTAATGGGTGT-3') at codon 132 for the IDH1 gene and (forward: 5'-AATTTTAGGACCCC CGTCTG-3', and reverse 5'-CTGCAGAGACAAGAGG ATGG-3') at codon 172 for the IDH2 gene. The PCR products were then sequenced on a 3130xl Genetic Analyzer (Applied Biosystems, Foster City, CA, USA) with a Big Dye Terminator v1.1 Cycle Sequencing Kit (Applied Biosystems) in accordance with the manufacturer's instructions.

\section{Statistical analysis}

Corrected metabolite concentrations of patients harboring mutant $I D H$ gliomas were compared to those harboring gliomas of wild-type $I D H$ using the Mann-Whitney $\mathrm{U}$ test. Receiver operating characteristic (ROC) curve was used to determine a cutoff for $2 \mathrm{HG}$ concentration to obtain maximal sensitivity and specificity to identify $I D H$ mutations. Kaplan-Meier analysis was used to compare overall survival. Tests for associations between different parameters were carried out by the chi-squared test for $2 \times 2$ contingency tables. $p<0.05$ was considered significant. Statistical analyses were performed using GraphPad Prism 6 software (GraphPad Software, http://www.graphpad.com).

\section{Results}

A summary of the patient characteristics of mutant and wild-type IDH groups is provided in Table 1. Median patient age was 53 years; Patients harboring mutant $I D H$ gliomas were younger than those with wild-type $I D H$ gliomas (45 years vs. 61 years, $p=0.0008$, Mann-Whitney $\mathrm{U}$ test). A majority (90.4\%) of the patients analyzed were newly-diagnosed patients. $I D H$ mutations were found in only 25 out of 52 cases (48.1\%), this was probably due to: the inclusion of primary glioblastoma and glioblastoma with oligodendroglioma component, failure to detect rare IDH1 and IDH 2 mutations by DNA sequencing, and/or selection bias due to the preoperative availability of MRS. There were more WHO grade II tumors (68.0\% vs. $25.9 \%$, $p=0.0024)$ and more patients were alive at last follow-up in the mutant IDH group ( $80.0 \%$ vs. $44.4 \%, p=0.0085)$.

Representative SVMRS spectra of mutant $I D H$ and wild-type $I D H$ gliomas are provided in Figure 2. Small

\begin{tabular}{|c|c|c|c|}
\hline \multirow[t]{2}{*}{ Characteristic } & \multicolumn{2}{|c|}{ Number of patients (\%) } & \multirow[t]{2}{*}{$p$ value } \\
\hline & Mutant IDH & Wild-type $I D H$ & \\
\hline Number & 25 & 27 & \\
\hline Men: Women & 14:11 & $14: 13$ & \\
\hline \multicolumn{4}{|l|}{ Age (years) } \\
\hline Median & 45 & 61 & $0.0008^{*}$ \\
\hline Range & $26-67$ & $28-77$ & \\
\hline Newly diagnosed & $22(88.0)$ & $25(92.6)$ & 0.9279 \\
\hline Recurrent & $3(12.0)$ & $2(7.4)$ & \\
\hline \multicolumn{4}{|l|}{ Pathological grade } \\
\hline WHO Grade II & $17(68.0)$ & $7(25.9)$ & $0.0024^{*}$ \\
\hline WHO Grade III & $8(32.0)$ & $20(74.1)$ & \\
\hline \multicolumn{4}{|l|}{ Outcome } \\
\hline Alive & $20(80.0)$ & $12(44.4)$ & $0.0085^{*}$ \\
\hline Dead & $5(20.0)$ & 15 (55.6) & \\
\hline
\end{tabular}

Results of unpaired t-test (age) and chi-squared tests (others). The values inside parentheses represent percentage of patients within each group. ${ }^{*} p<0.05$.

IDH: isocitrate dehydrogenase; WHO: World Health Organization.

peaks were detected at a chemical shift of about $2.25 \mathrm{ppm}$ in mutant $I D H$ gliomas. Both spectra have similar choline peaks, but these were not adjusted for choline.

Mutant $I D H$ gliomas showed a significantly higher accumulation of $2 \mathrm{HG}$ (median $5.077 \mathrm{mM}$ vs. $0.000 \mathrm{mM}$, $p=0.0002$, Mann-Whitney test). Mutant IDH gliomas also showed lower levels of GSH (median 1.849 vs. 2.409, $\mathrm{p}=0.0328$ ) and Glx (median 7.701 vs. 9.528, $\mathrm{p}=0.001$ ) compared to the wild-type IDH gliomas (Figure 3A). Levels of Ins, tNAA, tCho, and $\mathrm{tCr}$ were not significantly different between the two groups.

ROC curve analysis obtained a cutoff of $2 \mathrm{HG}=1.489 \mathrm{mM}$, with a sensitivity of $100.0 \%$ and specificity of $72.2 \%$, to detect $I D H$ mutations (Figure 3B). 2HG was detectable in all mutant $I D H$ gliomas, whereas in 10 out of 27 (37.0\%) wild-type IDH gliomas, $2 \mathrm{HG}$ was not detectable $(2 \mathrm{HG}=0)(p=0.0003)$. Five $(18.5 \%)$ of the wild-type IDH gliomas had an accumulation of $2 \mathrm{HG}$ higher than $1.489 \mathrm{mM}$; three gliomas (11.1\%) yielded a concentration of $2 \mathrm{HG}$ higher than $5 \mathrm{mM}$ (Figure 3B). A significantly longer overall patient survival was noted in gliomas with high accumulation of 2HG ( $p=0.0401$, Figure 4). Median survival was 823 days in glioma patients with low $2 \mathrm{HG}$; median patient survival was not reached in the glioma patients with high $2 \mathrm{HG}$. There was no significant difference in survival between patients harboring wild-type $I D H$ glioma patients with high $2 \mathrm{HG}$ accumulation ( $2 \mathrm{HG}>1.489 \mathrm{mM}$ ) vs. low $2 \mathrm{HG}$ accumulation ( $p=0.4894$, Kaplan-Meier curves not shown). Likewise there was no significant difference in survival between mutant IDH gliomas with high $2 \mathrm{HG}$ 

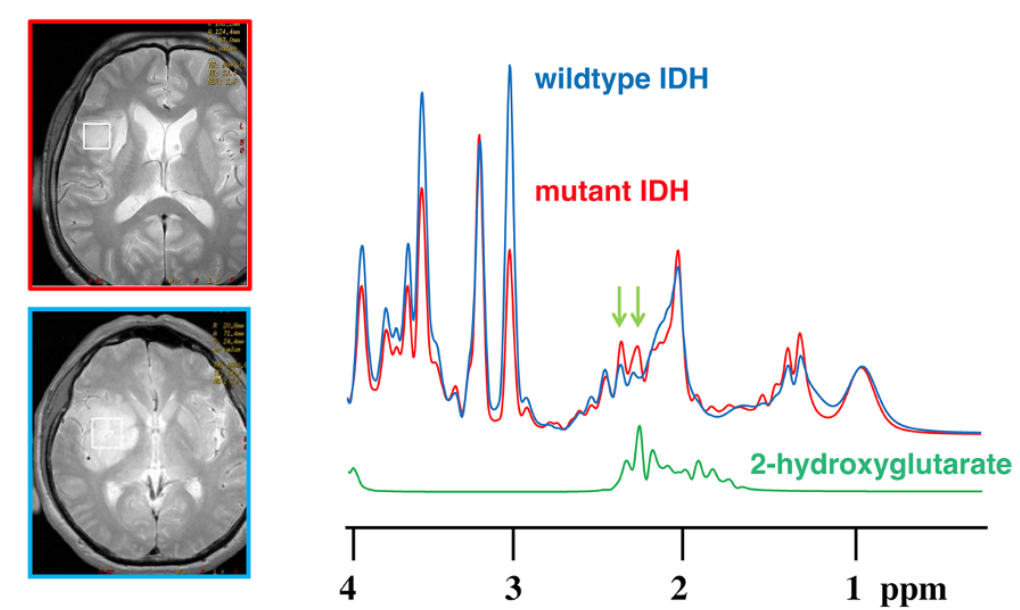

Figure 2 SVMRS spectra of mutant IDH and wild-type IDH gliomas. Representative SVMRS spectra of mutant IDH (red) and wild-type IDH gliomas (blue) are shown. Small peaks were detected at a chemical shift of about 2.25 ppm in mutant IDH gliomas. Both spectra have similar choline peaks, but these were not adjusted for choline.

accumulation (2HG $>5.077 \mathrm{mM})$ vs. low $2 \mathrm{HG}$ accumulation ( $\mathrm{p}=0.8815$, Additional file 1: Figure S1), although median survival has not been reached in either group.

\section{Discussion}

IDH1 and IDH2 enzymes catalyze oxidative decarboxylation of isocitrate to $\alpha$-ketoglutarate ( $\alpha-K G)$. Mutant IDH cannot catalyze this reaction and instead reduces $\alpha-K G$ to 2HG [3] (Figure 1). 2HG is oxidized by 2-hydroxyglutarate dehydrogenase (2-HGDH) back to $\alpha-K G$, and the mutation of 2-HGDH is known to cause 2-hydroxyglutaric aciduria [22]. A previous study has shown that glutamate is the main source of carbons for 2HG in mutant $I D H$ glioma cells [3].

In our study, 2HG was detected in all mutant $I D H$ gliomas. On the other hand, in a subset of wild-type $I D H$ gliomas, a high 2HG concentration was noted (Figure 3B). This may be attributed to false-positive results [23] or a failure to detect rare $I D H 1$ or $I D H 2$ mutations by DNA sequencing. However, a recent study showed millimolar concentrations of $2 \mathrm{HG}$ in wild-type $I D H$ breast cancer tissues. These accumulations were found to be associated with MYC, and carry a poor prognosis [24]. It remains to be seen if mechanisms of $2 \mathrm{HG}$ accumulation unrelated to $I D H$ mutation exist in gliomas as well.

It is known that $2 \mathrm{HG}$ is primarily derived from glutamine in mutant $I D H$ gliomas. Glutamine is hydrolyzed by glutaminase to produce glutamate, which is subsequently converted to $\alpha-K G[3,25]$. MYC is known to regulate glutamine utilization and glutaminase protein expression [26], and mutant IDH gliomas are known to have an increased expression of MYC [27]. Interestingly, we found less accumulation of Glx $(\mathrm{Glu}+\mathrm{Gln})$ in the mutant $I D H$ gliomas $(p<0.005$, Figure 3$)$, suggesting that glutamine consumption is contributing to the accumulation of $\alpha-K G$ and ultimately $2 \mathrm{HG}$ (Figure 1 ) in these tumors.

$2 \mathrm{HG}$ acts as a competitive antagonist of $\alpha-\mathrm{KG}$, causing inhibition of $\alpha$-KG-dependent dioxygenases. These include
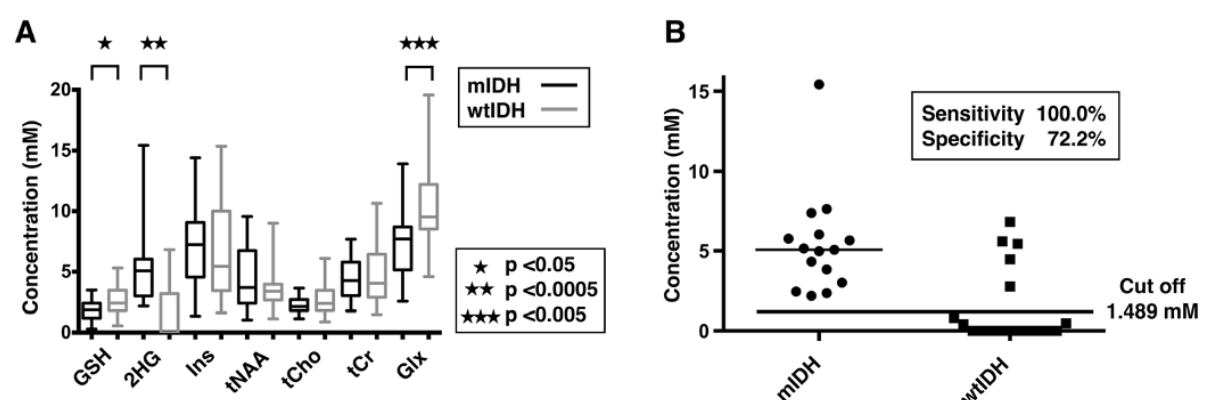

Figure $32 \mathrm{HG}$ is accumulated in mutant IDH gliomas. A) Comparisons of amount of metabolites in mutant IDH and wild-type IDH gliomas show markedly higher accumulation of 2-HG (median $5.007 \mathrm{mM}$ vs. $0.000 \mathrm{mM}$, Mann-Whitney test, $p=0.0002$ ) and lower concentrations of Glx $(p<0.05)$ in mutant IDH gliomas. B) ROC curve analysis revealed an optimal cutoff of 1.489 , with a sensitivity of $100.0 \%$ and specificity of $72.2 \%$. $2 \mathrm{HG}$ was detectable in all mutant IDH gliomas, whereas in 10 out of $27(37.0 \%)$ wild-type IDH gliomas, $2 \mathrm{HG}$ was not detectable $(2 \mathrm{HG}=0)(p=0.0003$, chi-squared test). Five out of 27 (10.3\%) wild-type IDH gliomas yielded a 2-HG concentration higher than $1.489 \mathrm{mM}$. 


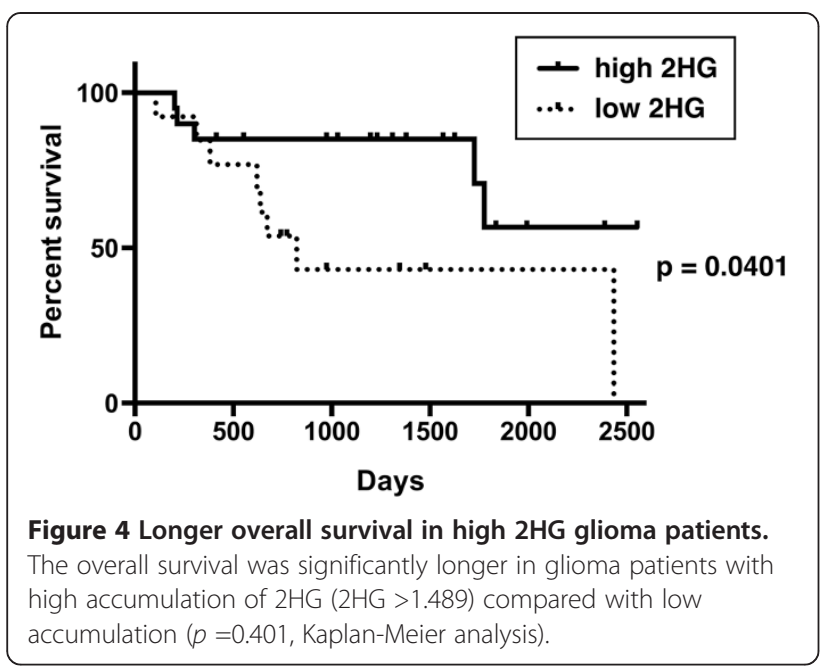

the JmjC domain-containing histone demethylases (KDMs), which cause histone demethylation [13-15], and the teneleven translocation (TET) family of DNA hydroxylases, which cause DNA demethylation [16,15]. This was consistent with data from the The Cancer Genome Atlas (TCGA) database, in which the proneural subgroup of glioblastoma was found to be enriched with $I D H$ mutations and display hypermethylation in a large number of loci [28]. A recent report has shown the stimulation of HIF prolyl hydroxylases by (R) enantiomer of $2 \mathrm{HG}$ in mutant $I D H$ immortalized astrocytes leads to a reduced level of HIF, but enhanced proliferation [29].

There are still others who hypothesize that mutant IDH is not tumorigenic, but actually makes tumor cells susceptible to death, evidenced by the longer survival of patients with IDH mutant glioma patients [30]. Mutant IDH1 and 2HG were shown to induce oxidative stress, cell-killing autophagy and apoptosis in a cell type specific manner [31]. New evidence suggests that IDH1 mutation inhibits the growth of glioma cells via GSH inhibition and generation of reactive oxygen species (ROS) [32]. This study, as well as previous MRS [10] and metabolomic [11] studies have shown that GSH is depleted in mutant IDH gliomas.

At least 8 different mutations of $I D H 1$ and $I D H 2$ are known in gliomas, at the IDH1 R132 and IDH2 R172 loci. $2 \mathrm{HG}$ can be detected in gliomas in vitro by massspectrometry or in vivo by MRS. One of the proposed advantages of detecting $2 \mathrm{HG}$ is that it would provide a screening for all mutations of $I D H 1$ and $I D H 2$, as all IDH mutations that are known to produce 2HG [33].

The 2HG molecule contains five nonexchangeable protons, giving rise to multiplets at three locations on $3 \mathrm{~T}$ MRS: approximately 4.02, 2.25, and $1.90 \mathrm{ppm}$ (Figure 2) [5]. The multiplet at $2.25 \mathrm{ppm}$ is larger than the other $2 \mathrm{HG}$ multiplets. The detection of this multiplet is complicated by the spectral overlap of Glu (2.43 ppm), Gln
(2.34 ppm), and GABA (2.28 ppm) [34]. Direct detection of the multiplet at $1.90 \mathrm{ppm}$ is difficult due to its proximity to NAA resonance at $2.01 \mathrm{ppm}$. Finally, the multiplet at 4.02 is partially overlapped with $\mathrm{Cr}(3.92 \mathrm{ppm}), \mathrm{PCr}$ (3.94 ppm), Ins (4.06 ppm), lactate (4.1 ppm) and free Cho (4.05 ppm) [5].

A false-positive rate of approximately $22 \%$ was observed by Pope et al. using the short-echo MRS with $\mathrm{TE}$ at $30 \mathrm{~ms}$ for the detection of 2HG [10]. This falsepositive rate can be reduced by using long-echo MRS with TE at $97 \mathrm{~ms}$ with the use of three-dimensional volume-localized basis (VLB) spectra, which has been shown to be optimal for detection of $2 \mathrm{HG}[5,6]$. A comparative study of PRESS sequences at short- $(35 \mathrm{~ms})$ and long- TE $(97 \mathrm{~ms})$ found long- TE to be superior for the following reasons: 1) it permits a more favorable voxel localization, and 2) it produces a well-defined narrow 2HG signal at $2.25 \mathrm{ppm}$, thereby leading to improved differentiation between 2HG and Glu, Gln, and GABA signals. Spectral fitting of PRESS data at $T E=97 \mathrm{~ms}$ was effective in minimizing the effect of macromolecule signals [5]. Five (18.5\%) wild-type IDH gliomas in this study were found to have high 2HG accumulation of more than $1.489 \mathrm{mM}$. Further analysis of these specimens by either mass spectrometry or ex vivo MRS is needed to determine whether these results could be attributed to false positive readouts.

Unambiguous detection of 2HG in mutant IDH glioma was achieved by $2 \mathrm{D}$ correlation spectroscopy (COSY) $[4,7,8]$ and J-difference spectroscopy [4]. However, these methods are less available clinically and involve longer acquisition time; 2D correlation MRS involves complex quantification and has less sensitivity [23]. We achieved $100 \%$ sensitivity of $2 \mathrm{HG}$ detection by short-echo MRS with modulation of $2 \mathrm{HG}$ resonances by spectral fitting. Less acquisition time enabled glioma patients, even those with relatively poor performance status, to undergo analysis. The biggest advantage of detecting $2 \mathrm{HG}$ by MRS is that it provides an opportunity for pre-surgical, noninvasive detection of $2 \mathrm{HG}$, thus reliably predicting $I D H$ status of gliomas before surgery. There is increasing interest that mutant $I D H$ patients may benefit from extensive surgery [35,36]. Also, $2 \mathrm{HG}$ is known to degrade after formalin fixation and paraffin embedding [12]. Ex vivo assessment of $2 \mathrm{HG}$ by MRS or mass spectrometry enable the analysis of homogeneous tumor tissue, but sample degradation and the necessity for treating tissues with reagents pose problems [23].

2HG detection by in vivo MRS may be utilized to evaluate response to glioma treatments. IDH mutations are known to be very tumor-cell-specific [37], and 2HG accumulation is found to be increased in tumor tissues compared to surrounding tissue. This leads to the notion that 2HG will not be assessable after surgical removal of 
a majority of the tumor. However, gliomas are pathologically known to be very infiltrative tumors, with individual glioma cells extending deep into adjacent brain tissues [38]. If $2 \mathrm{HG}$ can be detected in adjacent brain tissues by MRS, gliomas can be evaluated serially even after surgical removal of a majority of the tumor. Other metabolites such as Cho, Gln, Glu, lactate, NAA and $\mathrm{Cr}$ can be detected in conjunction with $2 \mathrm{HG}$, and this metabolic profile may be utilized to characterize tumor aggressiveness after chemotherapy and radiotherapy, at relapse and may even predict outcome [39].

Potent inhibitors of mutant IDH1 have been developed and are implicated in clinical trials in the United States. In vitro studies analyzing $2 \mathrm{HG}$ have shown a reduction of $2 \mathrm{HG}$ after usage of these inhibitors [40-42]. 2HG analysis by MRS would be an appropriate method to determine biological response of this drug in glioma patients.

\section{Conclusions}

Increasing evidence suggests that $2 \mathrm{HG}$ is an important oncometabolite in mutant $I D H$ gliomas. In vivo MRS has been shown to effectively measure $2 \mathrm{HG}$ and predict IDH status preoperatively in WHO grade II and grade III glioma patients. We found 2HG to be a positive prognostic factor in these gliomas. Further studies are warranted for other possible mechanisms of $2 \mathrm{HG}$ accumulation in gliomas.

\section{Additional file}

\section{Additional file 1: No survival difference between mutant IDH} glioma patients with high vs. low $2 \mathrm{HG}$ accumulation. No difference in survival between mutant IDH glioma patients with high $2 \mathrm{HG}$ accumulation $(2 \mathrm{HG}>5.077 \mathrm{mM}$ ) vs. low $2 \mathrm{HG}$ accumulation was noted ( $p=0.8815$ ). Median survival has not been reached in either group.

\begin{abstract}
Abbreviations
2HG: 2-hydroxyglutarate; 2-HGDH: 2-hydroxyglutarate dehydrogenase; 3 T: 3 tesla; a-ketoglutarate: a-KG; Cho: Choline; COSY: 2D correlation spectroscopy; Cr: Creatine; DNA: Deoxyribonucleic acid; GABA: $\gamma$ - aminobutyric acid; Gln: Glutamine, Glu, glutamate; Glx: Glutamine and glutamate; GPC: Glycerophosphocholine; GSH: Gluthathione; IDH: Isocitrate dehydrogenase; IHC: Immunohistochemistry; Ins: Myo-inositol; MRI: Magnetic resonance imaging; MRS: Magnetic resonance spectroscopy; NAA: N-acetylaspartate; NAAG: N-acetylaspartylglutamate; PC: Phosphocholine; PCr: Phosphocreatine; PRESS: Point-resolved spectroscopic sequence; ROC: Receiver operating characteristic; ROS: Reactive oxygen species; SD: Standard of deviation; S/R: Signal-to-noise ratio; SVMRS: Single voxel MRS; TCGA: The Cancer Genome Atlas; tCho: Total choline, tCr, total creatine; TET: Ten-eleven translocation; tNAA: Total NAA; VLB: Volume-localized basis; VOI: Volume of interest; WHO: World Health Organization.
\end{abstract}

\section{Competing interests}

The authors declare that they have no competing interests.

\section{Authors' contributions}

$\mathrm{MN}$ and $\mathrm{HI}$ designed the study; $\mathrm{HI}$ optimized spectral analysis for $2 \mathrm{HG}$ quantification; TN and $\mathrm{KO}$ performed the imaging; MN and $\mathrm{HI}$ performed metabolite analysis; AK and HT made pathological diagnoses; RO performed $\mathrm{IHC}$ and DNA sequencing; TK, $\mathrm{RO}, \mathrm{AH}$, and $\mathrm{YT}$ assessed patient survival; $\mathrm{MN}$ and $\mathrm{HI}$ wrote the manuscript; TN and YF approved the study design. All authors read and approved the final manuscript.

\section{Acknowledgements}

We acknowledge Drs. Kimihiko Nakamura, Taro Nishikawa, Shinya Jinguji and others for help with imaging. We acknowledge Joel Spencer for help with language editing.

\section{Author details}

Department of Neurosurgery, Brain Research Institute, University of Niigata, Niigata, Japan. ${ }^{2}$ Center for Integrated Brain Sciences, Brain Research Institute, University of Niigata, Niigata, Japan. ${ }^{3}$ Department of Pathology, Brain Research Institute, University of Niigata, Niigata, Japan.

Received: 22 August 2014 Accepted: 22 October 2014

Published online: 07 November 2014

\section{References}

1. Cancer Genome Atlas Research N (2008) Comprehensive genomic characterization defines human glioblastoma genes and core pathways. Nature 455:1061-1068, doi:10.1038/nature07385

2. Yan HPD, Jin G, McLendon R, Rasheed BA, Yuan W, Kos I, Batinic-Haberle I, Jones S, Riggins GJ, Friedman H, Friedman A, Reardon D, Herndon J, Kinzler KW, Velculescu VE, Vogelstein B, Bigner DD (2009) IDH1 and IDH2 mutations in gliomas. N Engl J Med 360:765-773, doi:10.1056/NEJMoa0808710

3. Dang $L$, White DW, Gross S, Bennett BD, Bittinger MA, Driggers EM, Fantin VR, Jang HG, Jin S, Keenan MC, Marks KM, Prins RM, Ward PS, Yen KE, Liau LM, Rabinowitz JD, Cantley LC, Thompson CB, Vander Heiden MG, Su SM (2009) Cancer-associated IDH1 mutations produce 2-hydroxyglutarate. Nature 462:739-744, doi:10.1038/nature08617

4. Andronesi OC, Kim GS, Gerstner E, Batchelor T, Tzika AA, Fantin VR, Vander Heiden MG, Sorensen AG (2012) Detection of 2-hydroxyglutarate in IDH-mutated glioma patients by in vivo spectral-editing and 2D correlation magnetic resonance spectroscopy. Sci Transl Med 4:116 ra4 1-10 doi:10.1126/scitranslmed.3002693

5. Choi C, Ganji S, Hulsey K, Madan A, Kovacs Z, Dimitrov I, Zhang S, Pichumani K, Mendelsohn D, Mickey B, Malloy C, Bachoo R, Deberardinis R, Maher E (2013) A comparative study of short- and long-TE (1)H MRS at 3 T for in vivo detection of 2-hydroxyglutarate in brain tumors. NMR Biomed 26:1242-1250, doi:10.1002/nbm.2943

6. Choi C, Ganji SK, DeBerardinis RJ, Hatanpaa KJ, Rakheja D, Kovacs Z, Yang XL, Mashimo T, Raisanen JM, Marin-Valencia I, Pascual JM, Madden CJ, Mickey BE, Malloy CR, Bachoo RM, Maher EA (2012) 2-hydroxyglutarate detection by magnetic resonance spectroscopy in IDH-mutated patients with gliomas. Nat Med 18:624-629, doi:10.1038/nm.2682

7. Elkhaled A, Jalbert LE, Phillips JJ, Yoshihara HA, Parvataneni R, Srinivasan R, Bourne G, Berger MS, Chang SM, Cha S, Nelson SJ (2012) Magnetic resonance of 2-hydroxyglutarate in $\mathrm{IDH} 1$-mutated low-grade gliomas. Sci Transl Med 4:116ra5 1-10 doi:10.1126/scitranslmed.3002796

8. Esmaeili MVR, Bathen TF (2013) 2-hydroxyglutarate as a magnetic resonance biomarker for glioma subtyping. Transl Oncol 6:92-98, doi:10.1593/tlo.12424

9. Lazovic J, Soto H, Piccioni D, Lou JR, Li S, Mirsadraei L, Yong W, Prins R, Liau LM, Ellingson BM, Cloughesy TF, Lai A, Pope WB (2012) Detection of 2-hydroxyglutaric acid in vivo by proton magnetic resonance spectroscopy in U87 glioma cells overexpressing isocitrate dehydrogenase-1 mutation. Neuro Oncol 14:1465-1472, doi:10.1093/neuonc/nos258

10. Pope WB, Prins RM, Albert Thomas M, Nagarajan R, Yen KE, Bittinger MA,

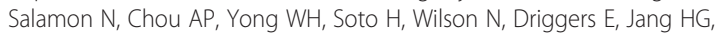
Su SM, Schenkein DP, Lai A, Cloughesy TF, Kornblum HI, Wu H, Fantin VR, Liau LM (2012) Non-invasive detection of 2-hydroxyglutarate and other metabolites in IDH1 mutant glioma patients using magnetic resonance spectroscopy. J Neurooncol 107:197-205, doi:10.1007/s11060-011-0737-8

11. Reitman ZJJG, Karoly ED, Spasojevic I, Yang J, Kinzler KW, He Y, Bigner DD, Vogelstein B, Yan H (2011) Profiling the effects of isocitrate dehydrogenase1 and 2 mutations on the cellular metabolome. Proc Natl Acad Sci U S A 108:3270-3275, doi:10.1073/pnas.1019393108

12. Sahm F, Capper D, Pusch S, Balss J, Koch A, Langhans CD, Okun JG, von Deimling A (2012) Detection of 2-hydroxyglutarate in formalin-fixed paraffin-embedded glioma specimens by gas chromatography/mass spectrometry. Brain Pathol 22:26-31, doi:10.1111/j.1750-3639.2011.00506.x 
13. Chowdhury R, Yeoh KK, Tian YM, Hillringhaus L, Bagg EA, Rose NR, Leung IK, Li XS, Woon EC, Yang M, McDonough MA, King ON, Clifton IJ, Klose RJ, Claridge TD, Ratcliffe PJ, Schofield CJ, Kawamura A (2011) The oncometabolite 2-hydroxyglutarate inhibits histone lysine demethylases. EMBO Rep 12:463-469, doi:10.1038/embor.2011.43

14. Lu C, Ward PS, Kapoor GS, Rohle D, Turcan S, Abdel-Wahab O, Edwards CR, Khanin R, Figueroa ME, Melnick A, Wellen KE, O'Rourke DM, Berger SL, Chan TA, Levine RL, Mellinghoff IK, Thompson CB (2012) IDH mutation impairs histone demethylation and results in a block to cell differentiation. Nature 483:474-478, doi:10.1038/nature10860

15. Xu W, Yang H, Liu Y, Yang Y, Wang P, Kim SH, Ito S, Yang C, Wang P, Xiao MT, Liu LX, Jiang WQ, Liu J, Zhang JY, Wang B, Frye S, Zhang Y, Xu YH, Lei QY, Guan KL, Zhao SM, Xiong Y (2011) Oncometabolite 2-hydroxyglutarate is a competitive inhibitor of alpha-ketoglutarate-dependent dioxygenases. Cancer Cell 19:17-30, doi:10.1016/j.ccr.2010.12.014

16. Figueroa ME, Abdel-Wahab O, Lu C, Ward PS, Patel J, Shih A, Li Y, Bhagwat N, Vasanthakumar A, Fernandez HF, Tallman MS, Sun Z, Wolniak K, Peeters JK, Liu W, Choe SE, Fantin VR, Paietta E, Lowenberg B, Licht JD, Godley LA, Delwel R, Valk PJ, Thompson CB, Levine RL, Melnick A (2010) Leukemic IDH1 and IDH2 mutations result in a hypermethylation phenotype, disrupt TET2 function, and impair hematopoietic differentiation. Cancer Cell 18:553-567, doi:10.1016/j.ccr.2010.11.015

17. Provencher S (1993) Estimation of metabolite concentrations from localized in vivo proton NMR spectra. Magn Reson Med 30:672-679, doi:10.1002/mrm.1910300604

18. Takado Y, Igarashi H, Terajima K, Shimohata T, Ozawa T, Okamoto K, Nishizawa M, Nakada T (2011) Brainstem metabolites in multiple system atrophy of cerebellar type: 3.0-T magnetic resonance spectroscopy study. Mov Disord 26:1297-1302, doi:10.1002/mds.23550

19. Louis DNOH, Wiestler OD, Cavenee WK (2007) WHO Classification of Tumours of the Central Nervous System. IARC, Lyon

20. Ashraf S, Noguera NI, Di Giandomenico J, Zaza S, Hasan SK, Lo-Coco F (2013) Rapid detection of IDH2 (R140Q and R172K) mutations in acute myeloid leukemia. Ann Hematol 92:1319-1323, doi:10.1007/s00277-013-1868-0

21. Capper D, Zentgraf H, Balss J, Hartmann C, von Deimling A (2009) Monoclonal antibody specific for IDH1 R132H mutation. Acta Neuropathol 118:599-601, doi:10.1007/s00401-009-0595-z

22. Struys EA, Salomons GS, Achouri Y, Van Schaftingen E, Grosso S, Craigen WJ, Verhoeven NM, Jakobs C (2005) Mutations in the D-2-hydroxyglutarate dehydrogenase gene cause D-2-hydroxyglutaric aciduria. Am J Hum Genet 76:358-360, doi:10.1086/427890

23. Andronesi OC, Rapalino O, Gerstner E, Chi A, Batchelor TT, Cahill DP, Sorensen AG, Rosen BR (2013) Detection of oncogenic IDH1 mutations using magnetic resonance spectroscopy of 2-hydroxyglutarate. J Clin Invest 123:3659-3663, doi:10.1172/JCl67229

24. Terunuma A, Putluri N, Mishra P, Mathe EA, Dorsey TH, Yi M, Wallace TA, Issaq HJ, Zhou M, Killian JK, Stevenson HS, Karoly ED, Chan K, Samanta S, Prieto D, Hsu TY, Kurley SJ, Putluri V, Sonavane R, Edelman DC, Wulff J, Starks AM, Yang Y, Kittles RA, Yfantis HG, Lee DH, loffe OB, Schiff R, Stephens RM, Meltzer PS et al (2014) MYC-driven accumulation of 2-hydroxyglutarate is associated with breast cancer prognosis. J Clin Invest 124:398-412, doi:10.1172/JCI71180

25. Seltzer MJ, Bennett BD, Joshi AD, Gao P, Thomas AG, Ferraris DV, Tsukamoto T, Rojas CJ, Slusher BS, Rabinowitz JD, Dang CV, Riggins GJ (2010) Inhibition of glutaminase preferentially slows growth of glioma cells with mutant IDH1. Cancer Res 70:8981-8987, doi:10.1158/0008-5472.CAN-10-1666

26. Gao P, Tchernyshyov I, Chang TC, Lee YS, Kita K, Ochi T, Zeller Kl, De Marzo AM, Van Eyk JE, Mendell JT, Dang CV (2009) c-Myc suppression of miR-23a/ b enhances mitochondrial glutaminase expression and glutamine metabolism. Nature 458:762-765, doi:10.1038/nature07823

27. Odia YOB, Bell WR, Eberhart CG, Rodriguez FJ (2013) CMYC expression in infiltrating gliomas: assoiations with IDH1 mutations, clinicopathological features and outcome. J Neurooncol 115:249-259, doi:10.1007/s11060-013-1221-4

28. Noushmehr H, Weisenberger DJ, Diefes K, Phillips HS, Pujara K, Berman BP, Pan F, Pelloski CE, Sulman EP, Bhat KP, Verhaak RG, Hoadley KA, Hayes DN, Perou CM, Schmidt HK, Ding L, Wilson RK, Van Den Berg D, Shen H, Bengtsson H, Neuvial P, Cope LM, Buckley J, Herman JG, Baylin SB, Laird PW, Aldape K, Cancer Genome Atlas Research N (2010) Identification of a CpG island methylator phenotype that defines a distinct subgroup of glioma. Cancer Cell 17:510-522, doi:10.1016/j.ccr.2010.03.017
29. Koivunen P, Lee S, Duncan CG, Lopez G, Lu G, Ramkissoon S, Losman JA, Joensuu P, Bergmann U, Gross S, Travins J, Weiss S, Looper R, Ligon KL, Verhaak RG, Yan H, Kaelin WG Jr (2012) Transformation by the (R)-enantiomer of 2-hydroxyglutarate linked to EGLN activation. Nature 483:484-488, doi:10.1038/nature10898

30. Zhu J, Zuo J, Xu Q, Wang X, Wang Z, Zhou D (2011) Isocitrate dehydrogenase mutations may be a protective mechanism in glioma patients. Med Hypotheses 76:602-603, doi:10.1016/j.mehy.2011.01.011

31. Gilbert MR, Liu Y, Neltner J, Pu H, Morris A, Sunkara M, Pittman T, Kyprianou N, Horbinski C (2014) Autophagy and oxidative stress in gliomas with IDH1 mutations. Acta Neuropathol 127:221-233, doi:10.1007/s00401-013-1194-6

32. Shi J, Zuo H, Ni L, Xia L, Zhao L, Gong M, Nie D, Gong P, Cui D, Shi W, Chen J (2013) An IDH1 mutation inhibits growth of glioma cells via GSH depletion and ROS generation. Neurol Sci Advance, online publishing doi:10.1007/s10072-013-1607-2

33. Rakheja D, Medeiros $\amalg$, Bevan S, Chen W (2013) The emerging role of d-2hydroxyglutarate as an oncometabolite in hematolymphoid and central nervous system neoplasms. Front Oncol 3:1-9, doi:10.3389/fonc.2013.00169

34. Govindaraju WYK, Maudsley AA (2000) Proton NMR chemical shifts and coupling constants for brain metabolites. NMR Biomed 13:129-153, doi:10.1002/1099-1492(200005)13:3<129::AID-NBM619>3.0.CO;2-V

35. Beiko J, Suki D, Hess KR, Fox BD, Cheung V, Cabral M, Shonka N, Gilbert MR, Sawaya R, Prabhu SS, Weinberg J, Lang FF, Aldape KD, Sulman EP, Rao G, McCutcheon IE, Cahill DP (2014) IDH1 mutant malignant astrocytomas are more amenable to surgical resection and have a survival benefit associated with maximal surgical resection. Neuro Oncol 16:81-91, doi:10.1093/neuonc/not159

36. Dunn GP, Andronesi OC, Cahill DP (2013) From genomics to the clinic: biological and translational insights of mutant IDH1/2 in glioma. Neurosurg Focus 34(E2):1-15, doi:10.3171/2012.12.FOCUS12355

37. Kato Y, Jin G, Kuan CT, McLendon RE, Yan H, Bigner DD (2009) A monoclonal antibody IMab-1 specifically recognizes IDH1R132H, the most common glioma-derived mutation. Biochem Biophys Res Commun 390:547-551, doi:10.1016/j.bbrc.2009.10.001

38. Claes A, Idema AJ, Wesseling P (2007) Diffuse glioma growth: a guerilla war. Acta Neuropathol 114:443-458, doi:10.1007/s00401-007-0293-7

39. Quon HBB, Alexander A, Murtha A, Abdulkarim B, Fulton D, Smerdely M, Johnson M, Urtasun R, Patel S, Ghosh S, Roa W (2011) Changes in serial magnetic resonance spectroscopy predict outcome in high-grade glioma during and after postoperative radiotherapy. Anticancer Res 31:3559-3565, doi:http://ar.iiarjournals.org/content/31/10.toc

40. Davis MPR, Popovici-Muller J, Gross S, Thorne N, Salituro F, Fantin V, Straley K, Su M, Dang L, Simeonov A, Shen M, Boxer MB (2012) ML309: A potent inhibitor of R132H mutant IDH1 capable of reducing 2-hydroxyglutarate production in U87 MG glioblastoma cells. Probe Reports from the NIH Mol Libr Progr, doi:http://www.ncbi.nlm.nih.gov/books/NBK153220/

41. Popovici-Muller J, Saunders JO, Salituro FG, Travins JM, Yan S, Zhao F, Gross S, Dang L, Yen KE, Yang H, Straley KS, Jin S, Kunii K, Fantin VR, Zhang S, Pan Q, Shi D, Biller SA, Su SM (2012) Discovery of the First Potent Inhibitors of Mutant IDH1 That Lower Tumor 2-HGin Vivo. ACS Med Chem Lett 3:850-855, doi:10.1021/ml300225h

42. Rohle D, Popovici-Muller J, Palaskas N, Turcan S, Grommes C, Campos C, Tsoi J, Clark O, Oldrini B, Komisopoulou E, Kunii K, Pedraza A, Schalm S, Silverman L, Miller A, Wang F, Yang H, Chen Y, Kernytsky A, Rosenblum MK, Liu W, Biller SA, Su SM, Brennan CW, Chan TA, Graeber TG, Yen KE, Mellinghoff IK (2013) An inhibitor of mutant IDH1 delays growth and promotes differentiation of glioma cells. Science 340:626-630, doi:10.1126/science.1236062

doi:10.1186/s40478-014-0158-y

Cite this article as: Natsumeda et al:: Accumulation of 2-hydroxyglutarate in gliomas correlates with survival: a study by 3.0-tesla magnetic resonance spectroscopy. Acta Neuropathologica Communications 2014 2:158. 